\title{
Numerical simulation of an osteoporotic femur
}

\author{
Before and after total hip arthroplasty
}

\author{
Mohamed Tellache*,** — Emmanuel Rixrath* \\ Patrick Chabrand* — Christian Hochard** — Martine Pithioux* \\ Sylvie Wendling-Mansuy*
}

* LABM UMSR 2164, Université de la Méditerranée

163 av. Luminy, F-13288 Marseille cedex 09

** LMA UPR 7051, 13 chemin J. Aiguier, F-13402 Marseille cedex 20

\begin{abstract}
Bone remodelling adapts bone geometry and properties under supported loadings. This optimization process is deteriorated by metabolic diseases like osteoporosis which involves femoral neck fractures and implies Total Hip Arthroplasty. Two finite element models are developed to evaluate the stress distribution within osteoporotic human femur bone tissue, and its influence on the stem stability. The geometries of human femur and prosthesis are obtained by helicoid scanner acquisition. The cortical bone was separated from the trabecular bone by apparent density threshold. The results obtained for osteoporotic femur show that the degradation of trabecular architecture causes high stresses in the anteroinferior zone of the cortical bone. For the femur with hip prosthesis, high stresses weak the bone tissue in the lateral zone of the proximal dyaphisis and in the medial zone of the distal part at the end of the stem.

RÉSUMÉ. Le remodelage osseux adapte la géométrie et les propriétés de l'os sous chargements. Ce processus est perturbé par des pathologies comme l'ostéoporose allant jusqu'à rupture du col du fémur nécessitant une arthroplastie totale de hanche. Deux modèles aux éléments finis sont développés pour évaluer la distribution des contraintes dans un fémur humain ostéoporotique et son influence sur la stabilité de l'implant. Les géométries du fémur et de la prothèse sont reconstruites à partir d'acquisition d'images scanner. Le tissu cortical se différencie du tissu trabéculaire par la valeur seuil de la densité apparente. Les résultats obtenus pour le fémur ostéoporotique montrent que la dégradation de l'architecture trabéculaire cause des contraintes élevées dans la zone antéro-inférieure du tissu cortical. Pour le fémur avec prothèse, les contraintes élevées affaiblissent le tissu osseux dans la zone latérale-proximale de la diaphyse et dans la zone médiale-distale à la pointe de l'implant.

KEYWORDS: 3D-reconstruction, finite element method, contact model.

MOTS-CLÉS : reconstruction $3 D$, méthode des éléments finis, modèle de contact.
\end{abstract}

DOI:10.3166/REMN.17.785-793 @ 2008 Lavoisier, Paris

REMN - 17/2008. Giens 2007, pages 785 to 793 


\section{Introduction}

The osteoarticular structure holds an important place in the locomotor's apparatus. It is essentially composed of bones. The structure of bone is designed to support the loads produced by daily activities and locomotion. In order to increase its strength and resist to daily loading, it adapts its mineralization and geometry by bone remodelling process. The bone remodelling can be deteriorated by metabolic diseases like osteoporosis which deteriorates bone strength. In Europe, the most consequences of osteoporosis are about 1700 bone fractures per day (World Health Organisation). Among these fractures, femoral neck fractures are the most recurrent and are the cause of life quality decrease and mortality rate increase. In general, femoral neck fracture is at the origin of the replacement of the entire hip articulation by Total Hip Arthroplasty (THA). The number of those implants tends to increase in the next decades due to the expectancy of life, but also to increase of THA for younger patients.

The osteoporosis weakens the bone strength essentially by the reduction of bone mass which is due to bone structure deterioration (Hajjar et al., 2004). The bone structure is reduced by a degradation of trabecular architecture, cortical envelop width decrease and its porosity increase (Bell et al., 1999). In the same manner, the first stability and durability of hip implants depend on bone strength which depends on the bone ability to adapt its structure and mineralization to new stress distribution. In consequence, the analysis of stress distribution in bone before and after THA was a major stake and required studies on bone tissue, biomaterials as well as problems of interface between biomaterials and bone tissue.

Our aims is to study the stress distribution within human femur bone tissue and also, the influence of the perturbation of this stress distribution by hip arthroplasty on its first stability. For this, two models of the same human femur were developed. The first represents a 3D finite element model of the femur without prosthesis. The second represents the same finite element model of the femur with a cemented stem to simulate a total hip arthroplasty in the bone environment.

This work falls under multidisciplinary project in collaboration with medical and biological teams, in order to study the failure mechanisms of bone related to strength loss, and also the orthopaedic device stability in their deteriorated environment.

\section{Method}

The finite element generation was performed from the geometry of a fresh human donor femur. This femur was obtained from the Laboratory of Anatomy of the Faculty of Medicine of Mediterranean University, Marseilles (responsible: P. Champsaur), and was conserved by Winkler intravenous injection and frozen at $20^{\circ} \mathrm{C}$. The geometry of the femur was obtained by helicoid scanner acquisition (General Electric LightSpeed Pro 16) from the Medical imagery service of 
LaTimone hospital, Marseilles $(0,625 \mathrm{~mm}$ native cuts thickness, $140 \mathrm{Kv})$. The scanner was used to generate voxel finite element model by CT2FEM (CT2FEM, 1996). This method allows assigning to each generated voxel, a density described by grey level from CT scans. Thus, each element has an effective bone density. The apparent density of the bone is calculated according to the method described by Taylor et al., 2002.

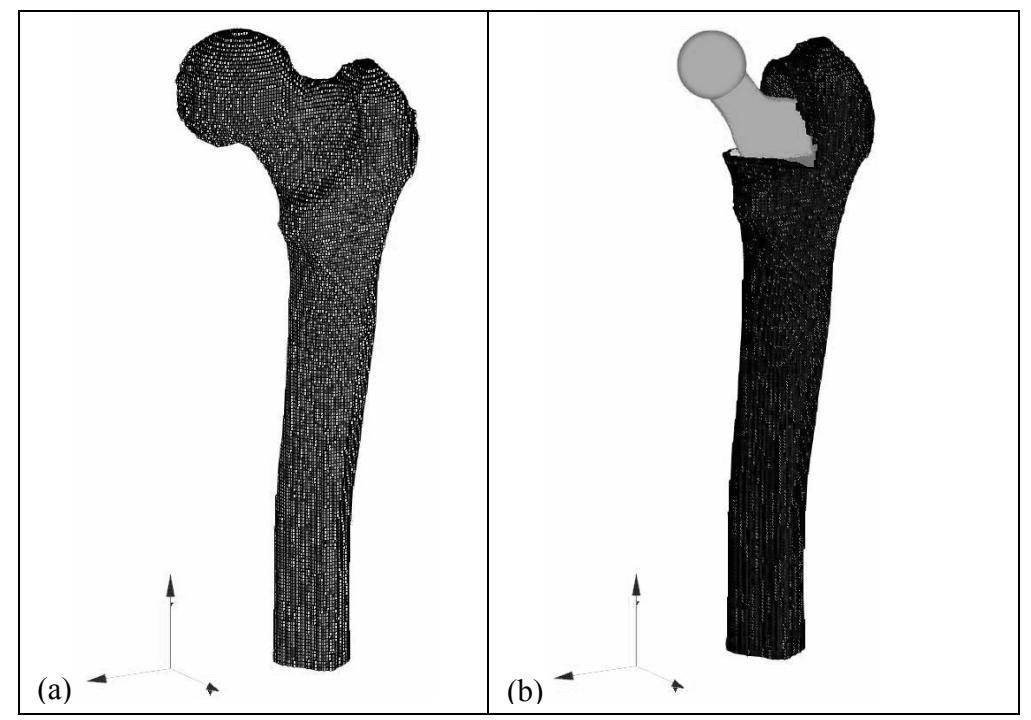

Figure 1. (a) Hexaedric mesh model of the whole femur, (b) Tetraedric mesh model of the PTH

Two separates tissues were considered in the femur model,, cortical bone and cancellous bone. The cortical bone was separated from the trabecular bone by apparent density threshold. For an apparent density greater than $0.2 \mathrm{~g} / \mathrm{cm} 3$, the bone was considered compact; under it was considered spongy (Bessho et al., 2006). The cortical bone was considered transversely isotropic (Huiskes et al., 1981; Katz and Meunier, 1987; Pithioux, 2000) in spite of the experimental results which show a certain orthotropy (Ashman et al., 1984). In this model, the compact bone elastic properties were calculated from density by a power law (Taylor et al., 2002). The grey level reported in scanners files was related to apparent density by a linear interpolation. The apparent density was then used to calculate elastic properties of cortical bone (Equation 1). Thus, the elastic properties of the kth element were given functions of its apparent density ( $\rho a p p ; k)$, the maximum apparent density in femur ( $\rho$ app;max), the maximum Young modulus in the ith direction of human bone (Ei;max) and the maximum shear modulus in the ijth plane of human bone (Gij;max). 


$$
E_{i, k}=E_{i \max } \frac{\rho_{a p p, k}^{2}}{\rho_{a p p \max }^{2}} ; G_{i j, k}=G_{i j \max } \frac{\rho_{a p p, k}^{2}}{\rho_{a p p \max }^{2}}
$$

The maximum values of cortical bone of elastic modulus are shown in Table 1. The transverse isotropy principal axis coincided with the diaphysaire axis at shaft level; with the cervical axis at femoral neck level, and with an axis in-between the two precedent axis at trochanter level.

Table 1. Maximal values of elastic properties in human bone (Pithioux M., 2002)

\begin{tabular}{|c|c|c|c|c|c|}
\hline \multicolumn{6}{|c|}{ Elastic modulus $(G P a)$} \\
\hline$E_{1}$ & $E_{2}$ & $E_{3}$ & $G_{21}$ & $G_{31}$ & $G_{32}$ \\
\hline 23 & 14 & 14 & 6.2 & 5.8 & 4.6 \\
\hline
\end{tabular}

The cancellous bone was assumed to present a large-scale isotropy (Brown and Ferguson, 1980), with strong variability according to studied region. This variation is strongly dependant on the orientation of trabeculae. In this model, the spongy part was considered isotropic and its elastic modulus was calculated from bone mineral density by the Taylor's power law (Equation 2). Thus, the elastic modulus of the kth element was given functions of its apparent density ( $\rho a p p ; k)$, the maximum apparent density in whole femur bone ( $\rho$ app;max), and the principal Young modulus given in Table $1(\mathrm{E} 1=23 \mathrm{GPa})$. The value of Poisson coefficient $(v=0.3)$ was taken from experimental data (Black and Hastings, 1998).

$$
E_{k}=E_{1} \frac{\rho_{a p p, k}^{2}}{\rho_{a p p \max }^{2}}
$$

The femur model was used to generate the cemented total hip replacement by introducing an implant into femoral diaphyse. The titanium prosthesis was simulated by a homogeneous isotropic elastic solid $(E=110000 \mathrm{MPa}, v=0.3)$. The prosthesis was fixed in bone by an acrylic cement, represented by an isotropic elastic solid ( $E$ $=2200 \mathrm{MPa}, v=0.3)$. The interface bone-cement was supposed to be bonded while a frictional contact was assumed between cement and stem. The Coulomb's law was used with a friction coefficient of $\mu=0.1$ (Nuño et al., 2006). The stem surface was considered as master and the ciment surface as slave surface.

The finite element model of the femur was meshed with 85624 hexahedral 8 nodes elements corresponding to three parts (the neck, trochanters, and shaft), each of them was composed of 28 parts corresponding to material groups with same 
elastic properties. The two bounded part of the prosthetic femur model were meshed with 395073 tetrahedral elements. The metallic stem was meshed with 64833 tetrahedral elements.

The two models simulated, in quasi-static loading, one leg stance phase during normal walking (Bergmann et al., 1993). The load case included joint load and muscles forces. These latter including abductors groups, Vastus-Lateralis and Tensor-Fascia-Lata, were applied to the anatomical attachment regions. Components of the forces are given in Table 2. The joint load was applied on femoral and implant head at the most upper node of the femoral head prosthesis according to Yoshida et al., 2002. The equations of both models were resolved using standard finite element method (ABAQUS, Hibbitt, Karlsson and Sorensen, Inc.).

Table 2. Joint load and muscles forces (Newton) during one leg stance of gait cycle (Bergmann et al., 2002)

\begin{tabular}{lcccc}
\hline & $\begin{array}{c}\text { Fx } \\
(\mathrm{N})\end{array}$ & $\begin{array}{c}\text { Fy } \\
(\mathrm{N})\end{array}$ & $\begin{array}{c}\mathrm{Fz} \\
(\mathrm{N})\end{array}$ \\
\hline Joint load & 338 & -208 & -1462.5 \\
\hline Muscle forces & & & & \\
\hline Tensor fascia & Distal & 4.18 & -5.85 & -158.84 \\
\hline Vastus Lateralis & Proximal & -60.19 & 96.97 & 110.35 \\
\hline Abductors & & 7.524 & 154.66 & -776.64 \\
\hline
\end{tabular}

\section{Results}

Frontal cut view of Von Mises stresses distribution in the cortical and cancellous regions of whole femur and THA are shown in Figure 2.

For the whole femur, the load applied to the femoral head was transmitted from trabeculae network to the inferior face of the femoral neck. In this region, the Von Mises stress ranged between $22 \mathrm{MPa}$ and $26 \mathrm{MPa}$. In the cancellous bone of the femoral neck, the stress magnitude is weaker than in the cortical envelop. $(\sim 10$ $M P a)$.

For the THA model, the Von Mises stresses in the medial side of the diaphysis vary from $5 \mathrm{MPa}$ under the stem neck to $28 \mathrm{MPa}$ at distal stem end. In the lateral side, the Von Mises stresses vary from $24 \mathrm{MPa}$ in the trochanter region to $7 \mathrm{MPa}$ at distal stem end. In the ciment, the Von Mises stresses vary from $8 M P a$ at the top of cement to $13 \mathrm{MPa}$ at distal stem end. 


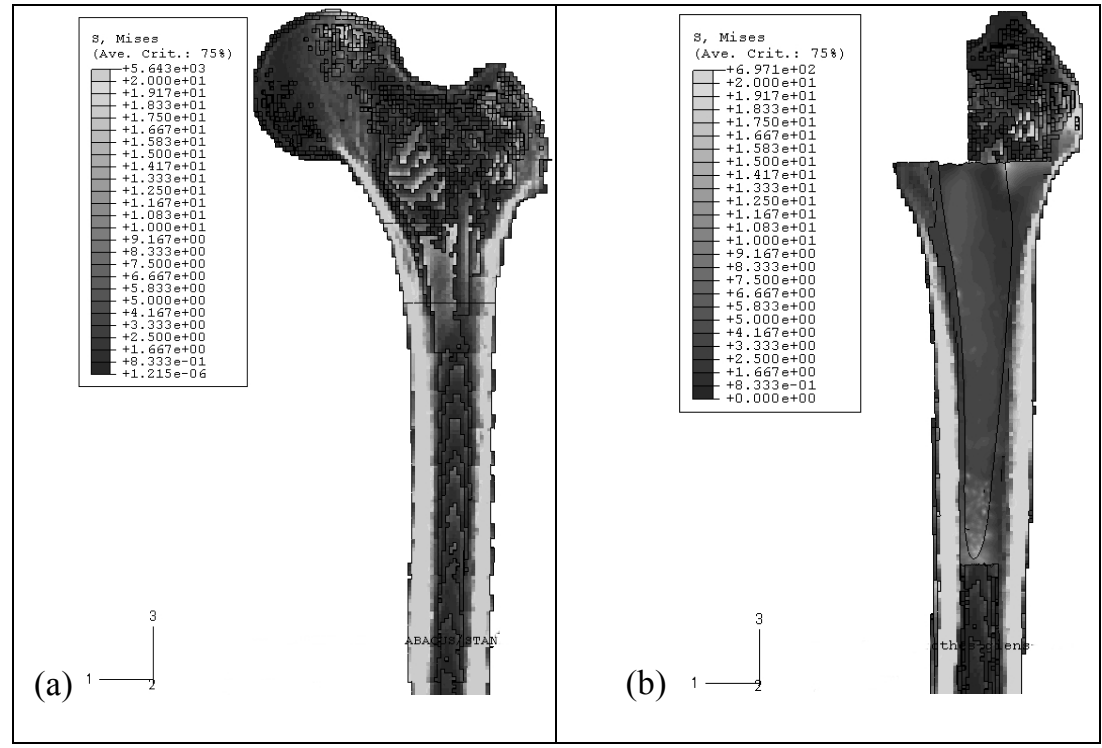

Figure 2. Frontal cut view of the Von Mises stress distribution (a) in osteoporotic femur (b) in THA

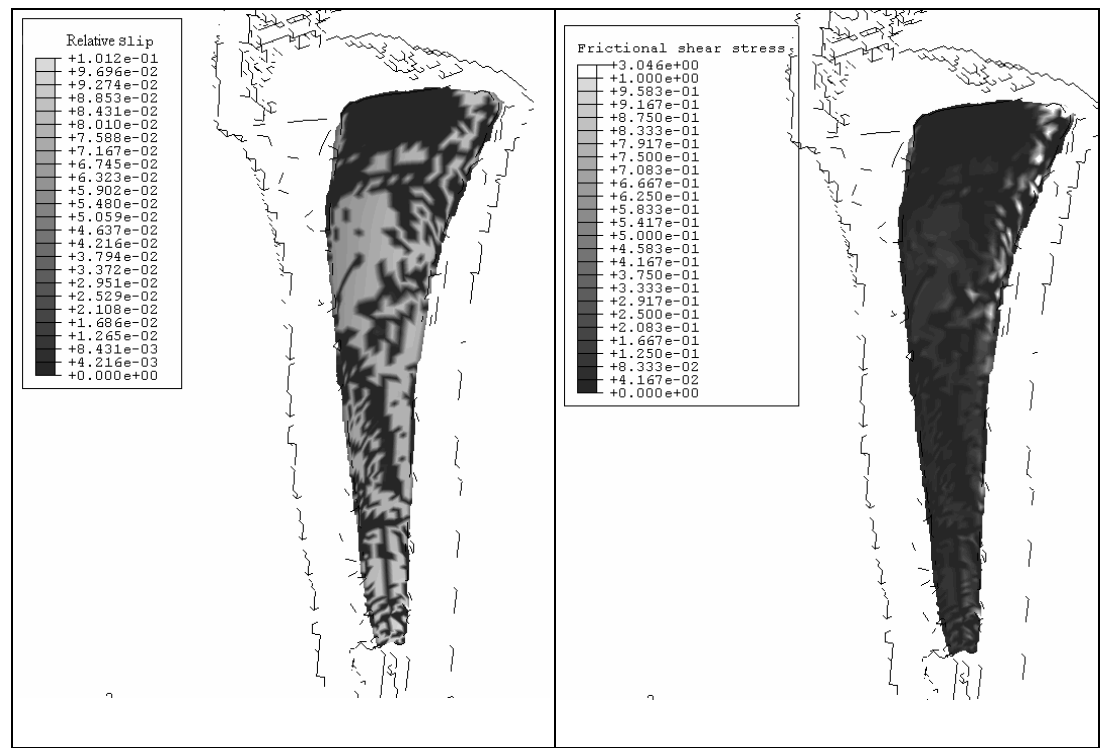

Figure 3. Frontal cut view of (a) the relative slip between stem and ciment (b) the frictional shear stress in THA model 
The contact formulation in the THA model allowed us to estimate the microslip, frictional shear, and contact stress, between the stem and the cement (see figure below). The stress was concentred in medial and lateral regions of the contact surface. The stress magnitude was in the range $[4 \mathrm{MPa}, 7 \mathrm{MPa}]$ and was highest at proximal lateral region. The relative slip between stem and cement corresponding to this level of stress was in the range [80 $\mu \mathrm{m}, 100 \mu \mathrm{m}]$.

\section{Discussion}

In the present study, two finite models were developed in order to analyse the stress distribution in human femur before and after hip replacement. The first model represented a voxel based finite element model of human femur generated from medical imaging. This model relates bone mineralization to elastic properties with a power law (Taylor et al., 2002) in order to simulate the transverse isotropy behaviour of human bone. The second model, so-called THA model, used the same femur finite element model in order to simulate the first stability of a cemented prosthesis in contact with bone after total hip arthroplasty.

The stress distribution calculated by the first model showed an overloading of the inferior region of the cortical neck. This is probably due to osteoporosis degradation of trabecular network which ensures the load transfer and distribution over all the cortical envelop of the femoral neck. Beck et al. (1999) found that the femoral neck was subjected to micro-structural degradation of the cortical tissue due essentially to its porosity increase and shell thickness decrease. Cortical bone degradation combined with overloading could explain femoral neck fractures due to osteoporosis.

Moreover, the THA model showed that the hip replacement significantly disturbs stress distribution within bone tissue and involves overloading in the great trochanter region and the distal stem end. In addition, the THA model showed an underloading of the medial proximal region which could explain bone mass lose and stem stability decrease. Such observations are mentioned by Rakotomanana et al., (1997). Furthermore, micromotions between stem and cement predicted by the THA model confirm those obtained by Raminaraka et al., (2000) using an isotropic bone model with a greater friction coefficient $(\mu=0.2)$.

In conclusion, the present models studied only the first stability without taking into account bone adaptation. However, these models will be enhanced in further studies by including bone remodelling process as developed by Rossi and Wendling (2007) in order to analyse long term stability and osteo-integration of orthopaedic devices in their environment. In addition, the use of other types of loading, such as stair-climbing, standing from a chair or jogging could give more information about peak stress and micromotion in bone femur and total hip arthroplasty. 


\section{Acknowledgements}

The authors want to thank Professor P. Champsaur and Doctor T. LeCorroller (Anatomy laboratory of medicine faculty, Mediterranean university) for having provided the bones and realized tomography acquisitions. We also thank S. Seguinel for her assistance in the drafting of this paper.

\section{References}

Ashman R.B., Cowin S.C., Van Buskirk W.C., Rice J.C., "A continuous wave technique for the measurement of the elastic properties of cortical bone", Journal of Biomechanics, vol. $17, \mathrm{n}^{\circ} 5,1984$, p. 349-361.

Bell K. L., Garrahan N., Kneissel M., Loveridge N., Grau E., Stanton M., Reeve J., "Cortical and Cancellous Bone in the Human Femoral Neck: Evaluation of an Interactive Image Analysis System", Bone, vol. 19, n 5, November 1996, p. 541-548.

Bergmann G., Graichen F., Rohlmann A., "Hip joint loading during walking and running, measured in two patients", Journal of Biomechanics, vol. 26, n 8, August 1993, p. 969-990.

Bessho M., Ohnishi I., Matsuyama J., Matsumoto T., Imai K., Nakamura K., "Prediction of strength and strain of the proximal femur by a CT-based finite element method", Journal of Biomechanics, vol. 40, n 8, 2007, p. 1745-1753.

Black J., Hastings G., Handbook of Biomaterial properties, Chapman et Hall, London, 1998.

Brown T.D., Ferguson A.B.J., "Mechanical property distributions in the cancellous bone of the human proximal femur", Acta Orthopaedica Scandinavica, vol. 51, 1980, p. 429-437.

Crabtree N., Loveridge N., Parker M., Rushton N., Power J., Bell K.L., Beck T.J., Reeve J., "Intracapsular hip fracture and the region-specific loss of cortical bone: analysis by peripheral quantitative computed tomography”, J Bone Miner Res, vol. 16, n 7, $2001 \mathrm{Jul}$, p. 1318-1328.

CT2FEM: Copyright (c) 1996 Laboratorio di Tecnologia Medica of Istituti Ortopedici Rizzoli, Bologna - Italy.

Hajjar R.R., Kamel H. K., “Osteoporosis for the Home Care Physician, Part 1: Etiology and Current Diagnostic Strategies", Journal of the American Medical Directors Association, vol. 5, n 3, May-June 2004, p. 192-196.

Huiskes R., Janssen J.D., Slooff, T.J., "A detail comparison of experimental and theoretical stress-analyses of a human femur", Mechanical properties of Bone, vol. 45, 1981, p. 211-234.

Katz J.L., Meunier A., "The elastic anisotropy of bone", Journal of Biomechanics, vol. 20, 1987, p. 1063-1070.

Nuño N., Groppetti R., Senin N., "Static coefficient of friction between stainless steel and PMMA used in cemented hip and knee implants", Clinical Biomechanics, vol. 21, $\mathrm{n}^{\circ} 9$, November 2006, p. 956-962. 
Pithioux M., Lois de comportement et modèles de rupture des os long. Thèse de doctorat, Université d'Aix Marseille II, 2000.

Rakotomanana R.L., Terrier A., Ramaniraka N., Rubin P., Leyvraz P.F., "Cemented and non cemented femoral stems: coupling effects between anchorage stability and bone adaptation", Congress of Orthopaedic Research Society, 1997, vol. 22, p. 855.

Raminaraka N.A., Rakotomanana L.R., Leyvraz P.F., The fixation of the cemented femoral components. Effects of stem stiffness, cement thickness and roughness of the cement bone surface, J Bone Joint Surg [Br], 2000, 82-B, p. 297-303.

Rossi J.M., Wendling-Mansuy S., “A topology optimization based model of bone adaptation”, Computer Methods in Biomechanics and Biomedical Engineering, 2007, 10, $\mathrm{n}^{\circ} 6$.

Taylor W.R., Roland E., Ploeg H., Hertig D., Klabunde R., Warner M.D., Hobatho M.C., Rakotomanana L., Clift S.E., "Determination of orthotropic bone elastic constants using FEA and modal analysis", J Biomech, vol. 35, 2002, p. 767-773.

Yoshida H., Faust A., Wilckens J., Kitagawa M., Fetto J., Chao E.Y., "Three-dimensional dynamic hip contact area and pressure distribution during activities of daily living", J. Biomech, vol. 39, 2005, p. 1996 - 2004. 
